\section{Memórias de um escravo esteta}

LUÍS FILIPE SOARES

Título: Uma Solidão Demasiado Ruidosa. Texto: a partir do romance de Bohumil Hrabal. Interpretação: António Simão. Cenografia e figurinos: Rita Lopes Alves. Desenho de luz: Pedro Domingos. Local: Incrível Almadense, Almada, 10, 11 e 12 de Julho de 2020.

Quando pela primeira vez li Uma Solidão Demasiado Ruidosa, do escritor checo Bohumil Hrabal, imaginei Hanta, o herói desse romance, falando comigo, contando-me a história da sua vida, a de um operário de uma prensa de papel que se tornara culto por acidente, ao entrar em contacto com os livros que destruía. Como seria essa voz? E os seus maneirismos? Eu conhecia a experiência de trabalho em empregos do fim da linha e a tendência era para ouvir a minha própria voz, para imaginar os meus gestos e tiques. Lembrava-me, inclusive, daquele período em que trabalhei como zelador de um edifício devoluto das Finanças, na Rua da Imprensa Nacional, com corredores que continham milhares de dossiês em estantes, nos quais se podia descobrir a fortuna, favorável ou inóspita, de milhares de cidadãos incógnitos. Por isso, de início, a voz do protagonista de Uma Solidão era a minha. Isto até o ouvir na voz de António Simão, momento em que ganhou uma dimensão que a minha imaginação não lhe poderia ter emprestado.

É evidente que um autor sabe tocar a universalidade da experiência quando, ao fim de poucas páginas, damos connosco a dizer: «Este sou eu!» Ou era eu, vinte anos atrás, entre o labirinto de arquivos das Finanças, fazendo a ronda ao mesmo tempo que lia Dostoievski ou Henry Miller. Durante o espetáculo, a performance de António Simão acomete-me no mesmo sentido. «Sei exatamente do que nos fala!», apetece-me berrar da plateia. «Desse cheiro! Dessa solidão!» E, de repente, diante dos meus olhos, surjo sozinho, de madrugada, no labirinto do edifício fantasma, a descobrir pela primeira vez Nietzsche, Lao-Tse ou Céline. Possivelmente porque, a par da universalidade, há nesta história uma noção de perfeito equilíbrio entre a beleza e a escatologia, entre a ignorância e a sapiência, entre a solidão e um grande prazer por se estar vivo e se amar os outros. O ser humano encontraria beleza até numa lixeira, se só aí estivesse confinado. Fechem-lhe todas as janelas e ele vira os olhos para dentro e sonha.

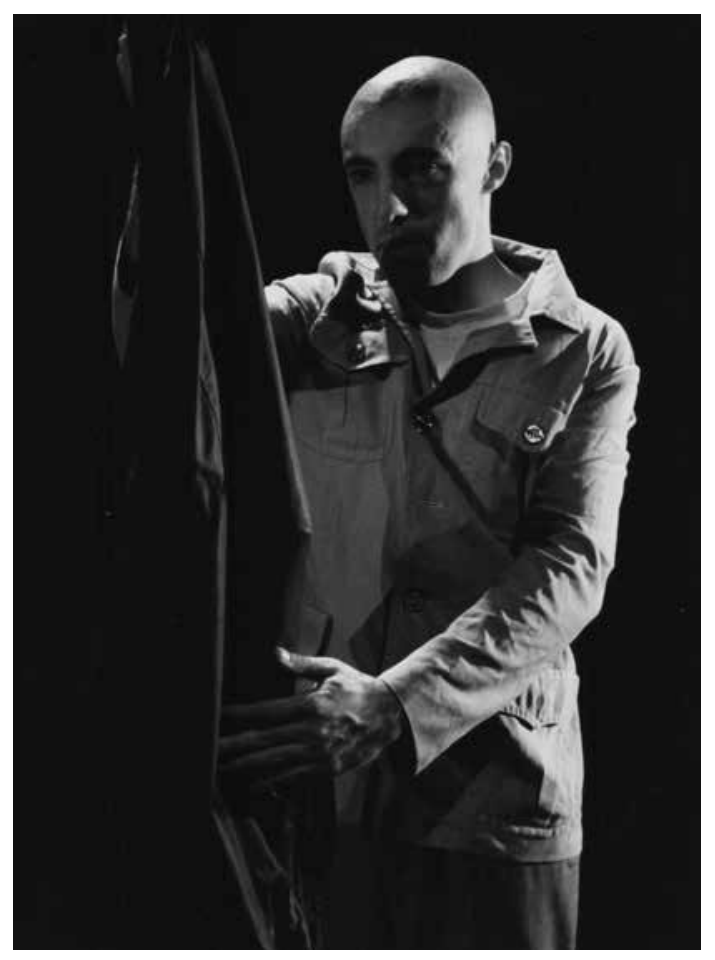
HRABAL, ARTISTAS UNIDOS (ANTÓNIO SIMÃO) [F] SUSANA PAIVA

Seja num edifício devoluto das Finanças, em Lisboa, ou na cave escura e húmida de uma oficina de prensagem de papel, em Praga. Ou como aquele indivíduo extraordinário, Mosab Abu-Toha, que no meio dos destroços dos bombardeamentos, em Gaza, fez uma biblioteca (Edward Said Public Library) e aí ensina as grandes obras da literatura. Ninguém vive sem essa contemplação. Enfiem um homem no calabouço e ele encontrará beleza nos traços, manchas e fendas da parede em branco.

No seu percurso de 35 anos como prensador de papel, o protagonista começa com o fim da Segunda Guerra Mundial, que lhe leva a amante cigana para os fornos crematórios, e acaba destituído pelo avanço da tecnologia e pela «Brigada Socialista do Trabalho». A narrativa é-nos entregue por António Simão como se tivéssemos encontrado Hanta num café e, depois de já termos bebido umas boas cervejas, ele nos começasse a contar a sua história de vida. O cenário é tão simples quanto o que essa experiência compreende: um balcão, que serve de bar ou de bancada de trabalho. Pensei no rico simbolismo que o romance contém e se alguns desses símbolos não poderiam estar presentes no cenário. Em especial, Hrabal tem um bestiário de que se socorre algumas vezes: as suas ratazanas lutadoras ou a rã que encontra no leite não poderiam figurar no 
palco como os guardiães desse templo, tão sedutor quanto ominoso, que é a oficina de Hanta? Mas, à medida que assistia à atuação de António Simão, percebia que se trata de um homem que nos conta a sua história num bar, sob a luz velada das reminiscências, ataviado numa farpela semelhante à dos antigos tipógrafos, e que tudo o mais seria acessório e apenas serviria para distrair. Com grande audácia, Simão pôs apenas em si a responsabilidade de nos transmitir as impressões deste operário, e o fascínio da experiência está em que consegue fazê-lo sem a ajuda de um grande aparato cénico.

Entre os episódios do romance, foram selecionados os mais dramatizáveis, embora por uma economia de tempo se tenham deixado de fora dois ou três que seriam igualmente interessantes. Refiro-me, por exemplo, à terceira história com a Mariinha, onde se nota claramente a influência dos contos de fadas e nos faz perceber como Hrabal é um mestre na criação de símbolos. Ou ao académico que faz uma tese sobre uma guerra que ocorre no subsolo entre dois grupos de ratazanas, uma metáfora da Luta de Classes. Ou ainda, já perto do final, o episódio com as sandálias da moda, mais uma anedota escatológica de Hrabal que ele conclui com uma revelação mística. Tirando estes, foram preservados todos os momentos importantes, como o romance com a cigana muda do papagaio de papel, os dois episódios da Mariinha e da sua beleza acidentalmente maculada pelo acidente da latrina, o crítico de teatro à procura de artigos de jornais antigos, o tio ferroviário e o seu brinquedo de fim de vida, a visita à fábrica de Brno, entre outros. A duração do espetáculo é perfeita e, para se incluir algum outro episódio do romance, teria de se retirar um destes, o que poderia levar a uma leitura um pouco diferente.

No dia 14 de julho, mediei uma conversa entre António Simão e o público, com grande curiosidade de perceber mais sobre as opções do ator e encenador que há 25 anos trabalha com os Artistas Unidos e outros nomes consagrados. Almada tem uma grande população de operários, sobretudo os ligados à Lisnave, e foi muito interessante ouvir as suas experiências. De repente, era como se tivéssemos na esplanada do Teatro Joaquim Benite vários Hantas contando-nos as suas histórias de vida. Entre eles, houve aquela senhora que nos contou que, na altura do 25 de Abril, os operários cultos não vinham de Lisboa ou Almada, mas sim de Vila Franca, e que foram esses que infundiram nos outros a sede do saber. Houve também o antigo serralheiro da Lisnave, a quem faltava o dedo de uma mão, perdido provavelmente nesse ofício, e que nos contou

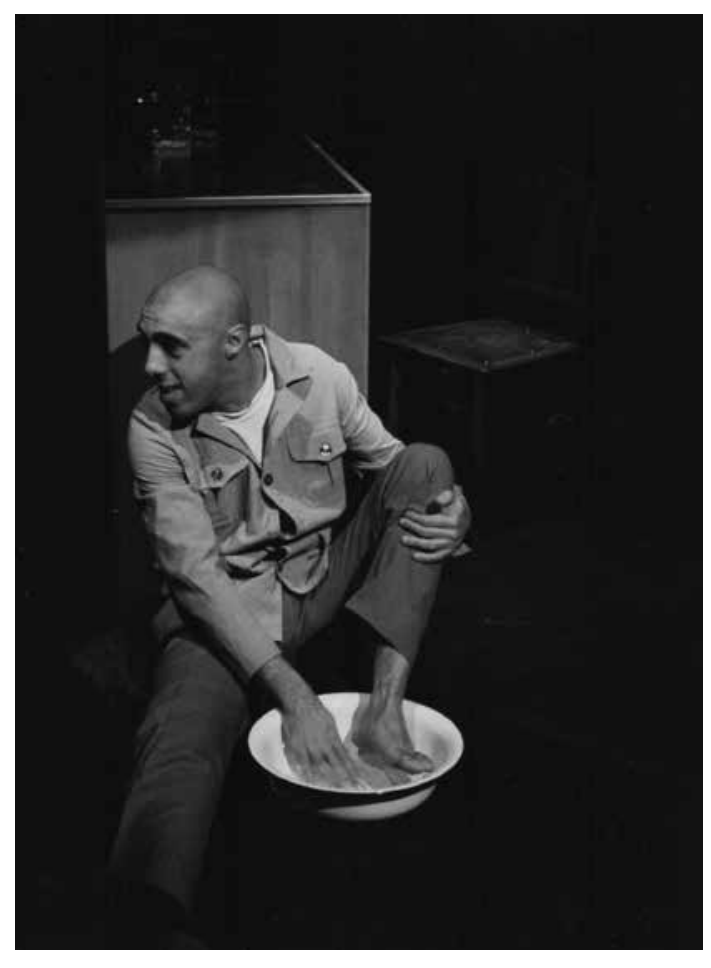
HRABAL, ARTISTAS UNIDOS (ANTÓNIO SIMÃO) [F] SUSANA PAIVA

a diferença entre as condições de segurança em Portugal e na Suécia, onde também trabalhou. Nesse momento debatíamos a questão: não terá Hrabal feito uma romantização do trabalho escravo? Não terá sido, de facto, melhor Hanta ser substituído pelo avanço tecnológico? Certamente ele, que encontrava a beleza e a poesia nas coisas mais insuspeitas, poderia igualmente encontrá-la em condições mais favoráveis. Mas o que a história de Hrabal nos comunica é precisamente a capacidade de encontrar a beleza e superar a solidão nas condições mais extremas. Daí «uma solidão demasiado ruidosa», porque está povoada de tesouros que ressoam vitalmente.

À medida que ia assistindo ao espetáculo, continuavam a surgir as memórias do labirinto de arquivos das Finanças, onde, de madrugada, me assustava com o som da madeira ou do plástico a estalar, os canos a verter e as lâmpadas a zumbir, e nas minhas mãos um Voltaire, um Rabelais ou um Swift que desfolhava avidamente. Pode um simples operário tornar-se culto? Talvez o grande enigma hoje seja: como é possível um operário não se tornar culto? O «operário das artes», António Simão, confessou-nos ter-se sentido, em tempos, embaraçado por apenas ler cerca de quatro livros por ano, as obras que estudava para fazer os 


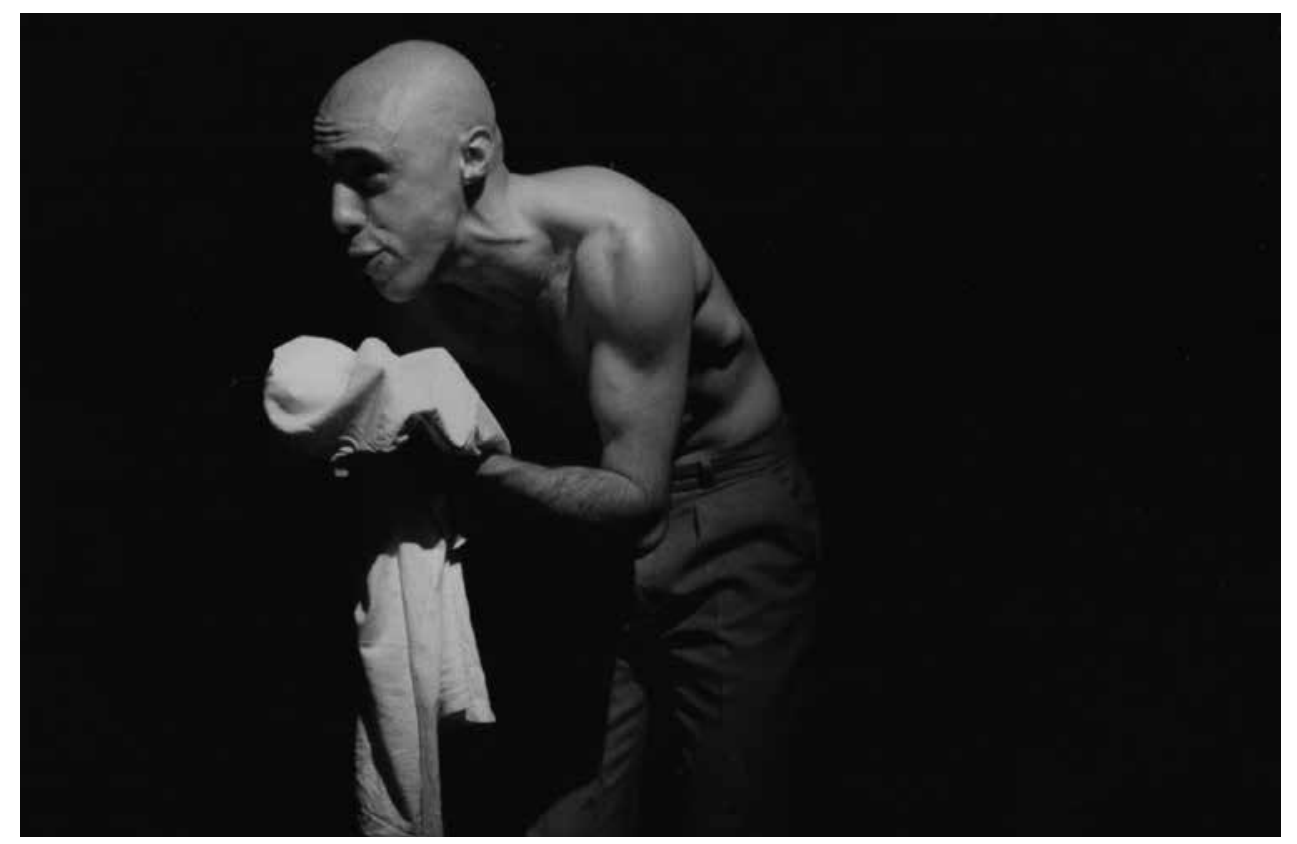

UMA SOLIDÃo DEMASIADO RUIDOSA, DE BOHUMIL HRABAL, ARTISTAS UNIDOS (ANTÓNIO SIMÃO), LF] SUSANA PAIVA

seus espetáculos. Um amigo informado ter-lhe-á então explicado que quatro livros bem estudados e decorados como ele o fazia era imenso. É esta paixão e deleite pelos livros que encontramos em Hanta. Ele saboreia cada passagem de uma grande obra e bebe canecas de cerveja para se sentir ainda mais extasiado, para tremer todo com as impressões que cada uma dessas passagens lhe traz. A sua não é, portanto, uma questão de querer tornar-se culto. Isso é perfeitamente secundário. Ele apenas quer ser lançado no prazer de sonhar acordado através do portal aberto por essas obras. Prova disso é que o seu conhecimento livresco nunca avança a sua situação profissional. Mesmo quando calha ganhar a lotaria, ele decide gastar rapidamente o dinheiro numa estância de esqui com Mariinha, por ter um certo desprezo à riqueza. Um magnata que conhece nessa estância convence-se mesmo de que Hanta é milionário devido ao à-vontade com que esbanja o pecúlio. Regressado à sua prensa, de bolsos vazios, sente certo alívio. Odeia o seu trabalho e ao mesmo tempo ama-o como se tivesse nascido apenas para fazer aquilo. Isto não é uma apologia da imobilidade social, mas um testemunho do espírito sonhador e introvertido que apenas se pode satisfazer como um ermita e asceta numa gruta dos tempos modernos, a sua oficina de prensagem numa cave escura e húmida. Tal como as ratazanas no subsolo,

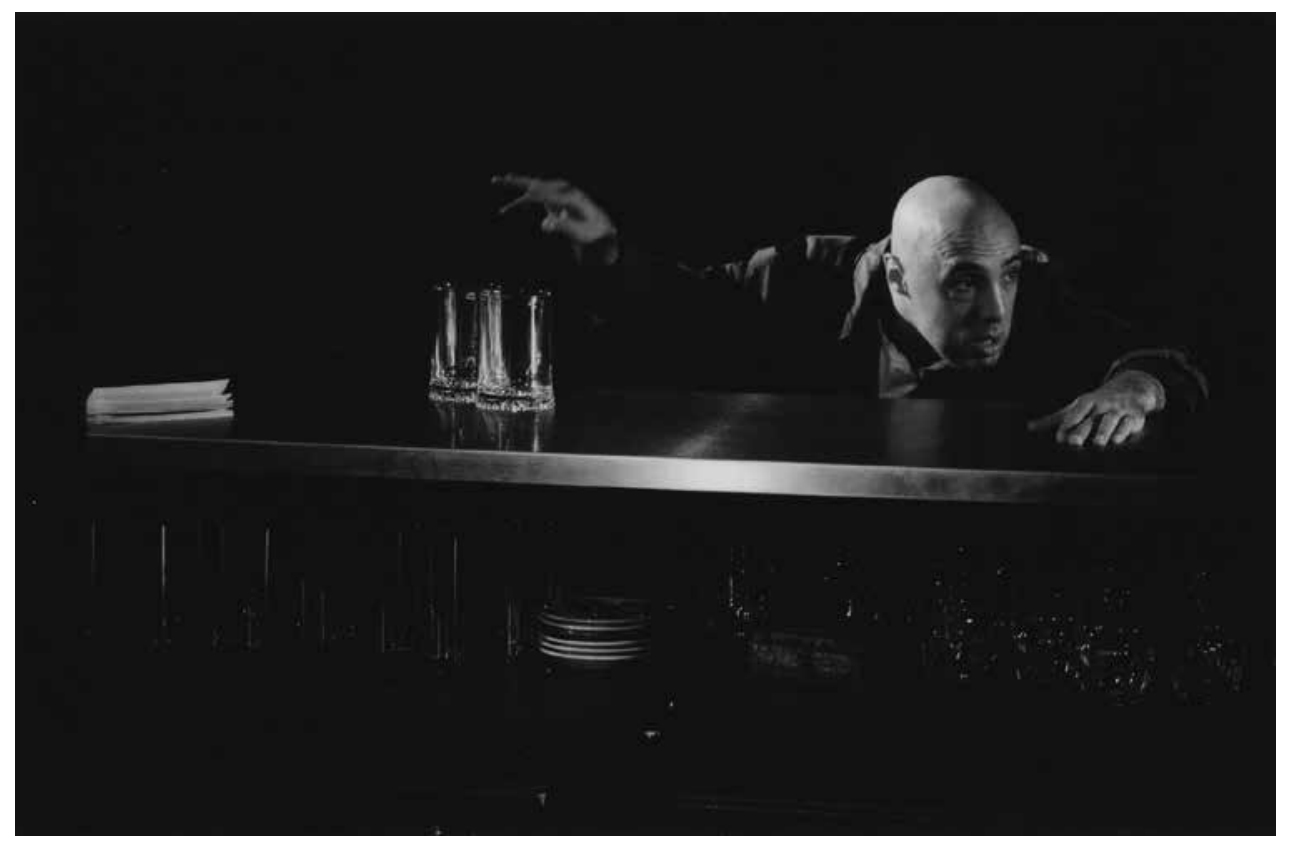

UMA SOLIDÃO DEMASIADO RUIDOSA, DE BOHUMIL HRABAL, ARTISTAS UNIDOS (ANTÓNIO SIMÃO), [F] SUSANA PAIVA

lá em cima os homens guerreiam-se e as ditaduras sucedem-se: primeiro o fascismo e depois o comunismo, cada qual com a sua lista de livros a abater, mas Hanta permanece fiel a si mesmo.

Durante o colóquio, António Simão contou-nos que, quando decidira comprometer-se a sério com a carreira de ator, o seu mentor advertiu-o de que haveria dias em que apenas teria para comer uma sopa. Ao que ele terá respondido que lhe parecia bem, que gostava de sopa. Esta é mais uma prova de que António Simão e Hanta são quase uma e a mesma «pessoa». A cigana cozinhava todos os dias a mesma refeição, e Hanta sentia-se feliz. $\mathrm{O}$ ator e encenador levou este texto à cena pela primeira vez quando tinha 23 anos (1997). Hoje, 23 anos depois, aos 46, Hanta tornou-se-lhe quase como uma segunda pele. Fez suas as palavras e os ensinamentos do operário checo. Na sua mente e corpo, traz comprimidas as obras de uma carreira. Perto do fim da história, depois do herói saber que vai ser despedido, há um encontro com um crítico de teatro. Distraído e míope como era, esse crítico tinha até então pensado que Hanta era duas pessoas: um velho e um novo. Por vezes, quando o encontrava, tomava-o pelo velho e perguntava-lhe como ia o novo e, outras vezes, o inverso. Nesse momento, o crítico percebe que Hanta é o novo e o velho ao mesmo tempo, o alfa e o ómega, o princípio e o fim. Daqui a 
vinte anos desejamos perguntar uma vez mais a António Simão o que sente ao interpretar o operário checo Hanta. Nessa altura ele terá vivido o alfa e o ómega desta personagem. Então, tal como o crítico distraído e míope da história, surpreender-nos-emos por, vinte anos antes, termos apenas captado metade da mensagem e de haver ainda tanto para nos maravilhar.

Uma das minhas memórias laborais reavivadas por esta história foi a de uma entrevista de emprego para a função de limpador de uma grande centrifugadora de argila. Informaram-me que, enquanto estivesse lá dentro, deveria gritar várias vezes cá para fora porque senão alguém poderia ligar a centrifugadora e eu próprio ser feito em massa. Quando perguntei se isso já tinha acontecido, responderam-me que havia pelo menos seis meses que não acontecia. Apesar de tudo, eu estava disposto a entrar na centrifugadora desde que pudesse continuar a dedicar-me à literatura nas minhas horas vagas. Hanta, que tinha a sorte de trabalhar com livros em vez de argila, entra voluntariamente na sua prensa quando sabe que vai ser destituído. Aciona o botão e começa a falar com o seu falecido avô, que, por sua vez, fala com outros antepassados e com Lao-Tse e Jesus. No fim, cada um de nós pode não ser mais que uns quantos livros prensados num cubo de $50 \mathrm{~cm}$ por $50 \mathrm{~cm}$, mas, até lá, é possível encontrar significado no grande absurdo aleatório em que essas páginas são escritas.

\section{REFERÊNCIAS BIBLIOGRÁFICAS}

HRABAL, Bohumil (1992) Uma Solidão Demasiado Ruidosa, Lisboa, Edições Afrontamento. 